\title{
FLOW ANALYSIS BY USING SOLENOID VALVES FOR AS(III) DETERMINATION IN NATURAL WATERS BY AN ON-LINE SEPARATION AND PRE-CONCENTRATION SYSTEM COUPLED TO A TUNGSTEN COIL ATOMIZER
}

\author{
José Y. Neira, Jenny Mendoza and Carlos G. Bruhn* \\ Departamento de Análisis Instrumental, Facultad de Farmacia, Universidad de Concepción, P.O. Box 237, Concepción, Chile
}

Recebido em 11/2/04; aceito em 27/8/04; publicado na web em 28/1/05

\begin{abstract}
A flow system coupled to a tungsten coil atomizer in an atomic absorption spectrometer (TCA-AAS) was developed for As(III) determination in waters, by extraction with sodium diethyldithiocarbamate (NaDDTC) as complexing agent, and by sorption of the As(III)-DDTC complex in a micro-column filled with $5 \mathrm{mg} \mathrm{C} 18$ reversed phase (10 $\mu \mathrm{L}$ dry sorbent), followed by elution with ethanol. A complete pre-concentration/elution cycle took $208 \mathrm{~s}$, with $30 \mathrm{~s}$ sample load time $(1.7 \mathrm{~mL})$ and $4 \mathrm{~s}$ elution time $(71 \mu \mathrm{L})$. The interface and software for the synchronous control of two peristaltic pumps (RUN/ STOP), an autosampler arm, seven solenoid valves, one injection valve, the electrothermal atomizer and the spectrometer Read function were constructed. The system was characterized and validated by analytical recovery studies performed both in synthetic solutions and in natural waters. Using a $30 \mathrm{~s}$ pre-concentration period, the working curve was linear between 0.25 and $6.0 \mu \mathrm{g} \mathrm{L} \mathrm{L}^{-1}(\mathrm{r}=0.9976)$, the retention efficiency was $94 \pm 1 \%\left(6.0 \mu \mathrm{g} \mathrm{L}{ }^{-1}\right)$, and the pre-concentration coefficient was 28.9 . The characteristic mass was $58 \mathrm{pg}$, the mean repeatability (expressed as the variation coefficient) was $3.4 \%(\mathrm{n}=5)$, the detection limit was $0.058 \mu \mathrm{g} \mathrm{L} \mathrm{L}^{-1}(4.1 \mathrm{pg}$ in $71 \mu \mathrm{L}$ of eluate injected into the coil), and the mean analytical recovery in natural waters was $92.6 \pm 9.5 \%(\mathrm{n}=15)$. The procedure is simple, economic, less prone to sample loss and contamination and the useful lifetime of the micro-column was between 200300 pre-concentration cycles.
\end{abstract}

Keywords: solenoid valves; arsenic(III); tungsten coil atomizer.

\section{INTRODUCTION}

In trace and ultra-trace analysis there is a need of reliable analytical methodologies for monitoring and screening purposes. The main system requirements are feasibility, speed, high degree of automation and cost-effectiveness. Based on the information obtained with these analytical approaches decisions can be made whether additional analysis with more time-consuming, expensive but also more accurate standard procedures is required. An important contribution to the improvement of analytical methodologies is the development of flow systems ${ }^{1}$, which have proved to be excellent tools for solution handling, and thanks to the rapidly growing progress in microelectronics and software ${ }^{2-4}$ they become today mature alternatives for a closed laboratory at a reduced scale. In this sense, injection and solenoid valves for liquid and gaseous samples ${ }^{5,6}$ are particularly convenient to design flow systems for speeding up solution analysis, requiring low sample and reagent volumes. Among their main features are suitable accuracy, precision, high sample throughput and low contamination. The coupling of flow based systems with atomic absorption spectrometry became a useful analytical alternative for on-line sample pretreatment and determination of trace and ultra-trace levels of heavy metals and metalloids in solution samples.

Within atomic spectrometric techniques during the last decade electrothermal atomic absorption spectrometry (ET-AAS) with a tungsten coil atomizer (TCA) has gained renewed interest as a supplementary atomization source to the flame $e^{7-12}$. In the search for an improvement in cost-effectiveness the study of alternative atomization means in ET-AAS becomes quite relevant. Tungsten coil atomization as proposed in 1988 by Berndt and Schaldach ${ }^{7}$ uses a

*e-mail: cbruhn@udec.cl double-layer coiled tungsten filament made for $150 \mathrm{~W}$ photo-projector lamps and offers some advantages to enable the determination of heavy metals and metalloids in solution samples, such as low power supply requirements, fast heating and low cost of the coils ${ }^{8}$. Conversely, it presents disadvantages that limit its application: i) this atomization alternative is not well known and in our region there is no commercial system on sale including a TCA; ii) a high temperature gradient is developed around the coil during atomization (so atomization is in non-isothermal condition); iii) the short residence time of the atomic cloud in the absorption volume limits the measurement time; and iv) matrix effects are produced in solid and gaseous phase, being this inconvenience the one that brings our interest to contribute to their resolution ${ }^{9-12}$. In the last decade, multicommutated flow systems ${ }^{13}$ allowed on-line pre-concentration and separation coupled with an electrothermal atomic absorption spectrometer and a TCA ${ }^{14,15}$. The potentialities of such systems were illustrated by on-line pre-concentration of $\mathrm{Pb}$ as a model element in a Chelex -100 resin minicolumn ${ }^{14}$, and by sorption of metal complexes in fullerene $\left(\mathrm{C}_{60}\right)$ aiming to the determination of $\mathrm{Cd}, \mathrm{Pb}$ and $\mathrm{Ni}$ in water samples ${ }^{15}$. These flow systems could also be useful to enable element speciation of different oxidation states [i.e., As(III) and $\mathrm{As}(\mathrm{V}) ; \mathrm{Cr}(\mathrm{III})$ and $\mathrm{Cr}(\mathrm{VI})]$.

It is well known that inorganic arsenic [As(III) and to a somewhat lesser extent, $\mathrm{As}(\mathrm{V})]$ is extremely toxic and may cause serious health effects, such as skin disorders and development of different cancers ${ }^{16}$. Arsenic is the first cause of acute toxicity and the second cause of poisoning by chronic toxicity ${ }^{17}$. Anthropogenic and natural levels of As are of concern in several areas throughout the world, and particularly in Central and Northern Chile because a few copper and gold smelters in this area are behind a large fraction of global As emissions, as established in a recent study of airborne As dispersed on small particles with an aerodynamic diameter $<10 \mu \mathrm{m}(\mathrm{PM} 10)^{18}$. This concern is magnified by the fact that Northern Chile soils and 
rivers in general are characterized by high As content. In Chile the maximum admissible concentration of total As in wastewaters which are dumped into surface continental or marine waters is $0.5 \mathrm{mg} \mathrm{L}^{-1}{ }^{19}$, while in drinking water this concentration is $50 \mu \mathrm{g} \mathrm{L}^{-1}{ }^{20}$. The provisional World Health Organization (WHO) guideline in drinking water was set at $10 \mu \mathrm{g} \mathrm{L}^{-1}$ in 1993; it was adopted by European Union member states and by the U.S. EPA, and based on health concerns alone it would still be lower ${ }^{21}$.

The aim of this work was to design a reliable and efficient flow system to enable fast on-line pre-concentration and matrix separation of As(III) by on-line sorbent extraction ${ }^{22-24}$ coupled to a tungsten coil atomizer in atomic absorption spectrometry (TCA-AAS). Besides the use of a simple and low cost atomizer, some advantages of this approach are: i) sample treatment and full delivery of the analyte into the TCA with minimum exposure to the environment; ii) freedom from interfering matrix components during the atomization step; and iii) a reasonable sensitivity enhancement. Moreover, the stability of reagents and of the complex under the analytical conditions is not of real concern because the time between reaction and sorption is typically of the order of $\mathrm{ms}$; hence, equilibrium need not be attained because of the exact timing of all processes. Solutions are handled via solenoid valves and an injection valve, and the coupling with the TCA is done through an autosampler arm. The design of the system was adapted to work in parallel with the TCA operation time required for a typical temperature programme and to enable the full analyte injection into the coil. Bonded silica with reverse phase $\mathrm{C} 18$ functional groups was selected as the sorbent material and sodium diethyldithiocarbamate (NaDDTC) was used as chelating agent of As(III). The As(III)-DDTC complex was sorbed in a C18 reverse phase microcolumn $^{24}$, followed by elution with ethanol and injection of the eluate into the TCA with a controlled air flow. Arsenic(V) must be prereduced to As(III) to form this complex and this procedure is now in study in this laboratory to enable an on-line pre-reduction for differential determination of As(III) and total As. The software and hardware to handle peristaltic pumps, injection and solenoid valves, autosampler arm, and spectrometer Read function, as well as the tungsten coil power supply program and control was developed based on a previous interface built in this laboratory ${ }^{25,26}$.

\section{EXPERIMENTAL PART}

\section{Instrumentation}

A Perkin Elmer (PE) Model 1100 atomic absorption spectrometer (Überlingen, Germany) was equipped with a $\mathrm{TCA}^{7}$ installed on a vertical-transversal alignment stance bound to the base of a laboratorymade quick-change mount system ${ }^{9-12}$. The limiting time resolution of the spectrometer was $0.02 \mathrm{~s}$ and peak height absorbance was measured throughout at the 193.7-nm As resonance line (EDL System 2 lamp, PE). The absorbance was background corrected with a deuterium arc, and time-resolved absorption signals were printed out. The measurement time was $1.0 \mathrm{~s}$. Lamp current and slit-width settings corresponded to manufacturer's recommendations. The arm of an autosampler AS-40 (PE) was used for sample introduction into the coil ${ }^{25}$.

The double-layer coiled tungsten filament $(150 \mathrm{~W}$, Osram, München, Germany, Part $N^{\circ} 64633$ HXL) was heated by a programmable power supply with voltage feedback circuit (Anacom Equipment and System, São Bernardo do Campo, SP, Brazil) and run with a PC computer (Pentium $100 \mathrm{MHz}$ ). A software was written in Quick-Basic $4.0^{27}$ to enable coordinated operation of the TCA power supply and synchronous management of two peristaltic pumps, the position of the autosampler arm, the setup of seven three-way solenoid valves and one five-port injection valve, and the READ function of the spectrophotometer. The hardware for this task was based on a PCL-711S PC-Multilab package (Advantech Co., Ltd, Taiwan, Part $N^{\circ} 2003711020$ Rev. A2) which was connected to a control interface designed in our laboratory ${ }^{25,26}$. The software was designed to select the number of program steps, the voltage-time conditions in each step, and it was controlled through the parallel port (LPT2). Argon-hydrogen (90:10)(Indura, Santiago, Chile) for TCA-AAS was used as purge gas at an optimum flow rate of $1.5 \mathrm{~L}$ $\min ^{-1}$ throughout ${ }^{12}$.

The flow system (Figure 1) consisted of two Ismatec MCP ISM726 peristaltic pumps (variable speed drive, 1 - $240 \mathrm{rpm})(\mathbf{P 1}$ and P2, respectively), seven three-way solenoid valves (NResearch Inc., USA, Part $\mathrm{N}^{\circ}$ 161T031), one five-port injection valve (PE, Part $\mathrm{N}^{\circ}$ B050-7914) and the autosampler arm. Pump 1 (P1) was used with four channels; three are furnished with Tygon pump tubing to propel sample solution (1.42 mm i.d., $3.4 \mathrm{~mL} \mathrm{~min}^{-1}$ ), hydrochloric acid solution $\left(0.76 \mathrm{~mm}\right.$ i.d., $\left.1.2 \mathrm{~mL} \mathrm{~min}^{-1}\right)$ and air $(1.42 \mathrm{~mm}$ i.d., 3.5 $\left.\mathrm{mL} \mathrm{min}^{-1}\right)$, respectively; the fourth is furnished with silicone tubing (1.02 mm i.d., $1.9 \mathrm{~mL} \mathrm{~min}^{-1}$ ) to propel the chelating solution (diethyldithiocarbamate, DDTC). Pump 2 (P2) was used with three channels; two are furnished with Tygon pump tubing to propel the washing medium (water) both in the reverse direction ( $1.42 \mathrm{~mm}$ i.d., $3.4 \mathrm{~mL} \mathrm{~min}^{-1}$ ) with respect to the micro-column (MC) and in the load direction (1.42 $\mathrm{mm}$ i.d., $\left.3.7 \mathrm{~mL} \mathrm{~min}^{-1}\right)$; the third is furnished with silicone tubing $\left(0.76 \mathrm{~mm}\right.$ i.d., $\left.1.05 \mathrm{~mL} \mathrm{~min}^{-1}\right)$ to propel the eluent (ethanol). A precolumn (PC) made of polypropylene tubing ( $2.0 \mathrm{~mm}$ i.d., $5 \mathrm{~mm}$ long) filled with $10 \mathrm{mg}$ octadecyl bonded phase silica gel (SUPELCO, 40-63 $\mu$ ) was connected in the DDTC tubing before the respective solenoid valve to pre-clean the DDTC solution from possible traces of As(III)- and metal-DDTC chelates. The packing of this PC was changed after approximately 300 preconcentration cycles. The manifold was mounted on with polyethylene tubing of $0.8 \mathrm{~mm}$ i.d. Five Tee inert connectors (NResearch Inc., Part $\mathrm{N}^{\circ}$ FITM123)(Fig. 1, C1-5,) were used to mix on-line the sample and acid solutions, the acidified sample with the DDTC solution, to introduce the washing medium, the ethanol and the air into the flow system, respectively. A $16 \mathrm{~cm}$ polyethylene tubing ( $0.8 \mathrm{~mm}$ i.d.) was used as linear reactor before the injection valve

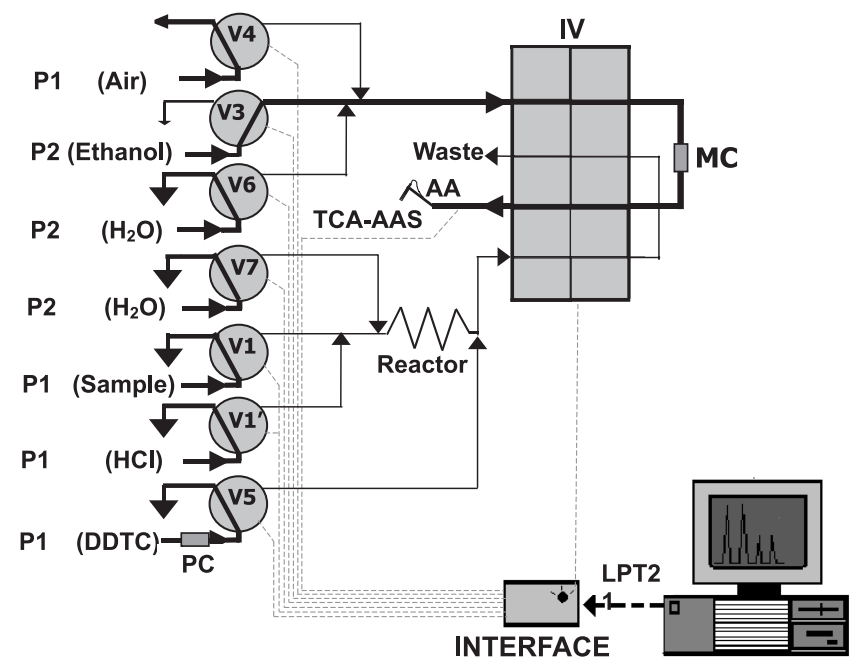

Figure 1. Flow diagram for As(III) determination by on-line separation and pre-concentration coupled to TCA-AAS (Elution step). $(\boldsymbol{P}=$ peristaltic pump $; \boldsymbol{V} \mathbf{1}-\boldsymbol{V 7}=$ solenoid valves $; \boldsymbol{I V}=$ injection valve $; \boldsymbol{P C}=$ pre-column $;$ $\boldsymbol{M C}=$ micro-column $; \boldsymbol{A A}=$ autosampler arm $; \boldsymbol{T C A}-\boldsymbol{A} \boldsymbol{A} \boldsymbol{S}=$ atomic absorption spectrometer with tungsten coil atomizer) 
(IV), and the later was used for the pre-concentration/separation and elution steps with the MC connected in the valve sample loop. The laboratory-made MC was a cylindrical column made of polypropylene tubing ( $2.0 \mathrm{~mm}$ i.d.) filled with $5 \mathrm{mg}$ octadecyl bonded phase silica gel (SUPELCO, 40-63 $\mu$ ). The packing was sealed at both ends by push-fit connections made with a screen of polyamide cloth held tightly with a strip of PTFE tape at one end of a PTFE tubing connector (50 mm x $0.9 \mathrm{~mm}$ i.d.) and with threaded fitting for connection to the IV at the other end. The MC and both tubing connectors were tightly held together with PTFE tape. The reverse phase bed was $3 \mathrm{~mm}$ long for a $10 \mu \mathrm{L}$ volume of dry solid substrate. To minimize dispersion of the analyte in the MC, the sample solution (on-line adjusted in $\mathrm{pH}$ ) and the eluent passed through the column in counter-flow. The sample flow-rate through the MC was checked regularly and if a drop in flow-rate was noticed due to back-pressure in the filling, the column was replaced by a new one. Dispersion was further restricted by using a $30 \mathrm{~cm}$ length of $0.38 \mathrm{~mm}$ i.d. Tefzel ETFE tubing to connect the IV to the tip of the autosampler arm. The subsequent use of ethanol at a flow-rate of $1.1 \mathrm{~mL} \mathrm{~min}^{-1}$ was sufficient to elute the sorbed As(III)-DDTC complex into the coil in two periods of $2 \mathrm{~s}$, each one followed by an air flow to deliver the eluate into the coil, and by several alternated drying and cooling periods to enable smooth eluate drying without physical loss from the coil. As is described below, after the elution step, two rinse steps and a water removal step by an air flow were used to recover the MC for the next pre-concentration cycle.

A WTW pH meter (Weilheim, Germany) model pH 522 with an Ingold 405 glass electrode was used.

\section{Reagents and materials}

Most reagents were of analytical-reagent grade (Merck, Darmstadt, Germany), except for $\mathrm{HNO}_{3}$ and $\mathrm{HCl}$ which were further purified in a quartz sub-boiling still and stored in quartz, and $\mathrm{As}_{2} \mathrm{O}_{3}$ which was Suprapur grade (Merck). Ultrapure (u.p.) water (18 M $\Omega-\mathrm{cm})$ was used throughout. Arsenic(III) stock solution $\left(1000 \mu \mathrm{g} \mathrm{mL} \mathrm{m}^{-1}\right)$ was prepared by dissolving $1.320 \mathrm{~g}$ of $\mathrm{As}_{2} \mathrm{O}_{3}$ in $25 \mathrm{~mL} 20 \% \mathrm{~m} / \mathrm{v} \mathrm{KOH}$ solution, neutralizing with $20 \% \mathrm{v} / \mathrm{v} \mathrm{H}_{2} \mathrm{SO}_{4}$ and diluting to $1000 \mathrm{~mL}$ with $1 \% \mathrm{v} / \mathrm{v} \mathrm{H}_{2} \mathrm{SO}_{4}$. A working standard solution of $10 \mu \mathrm{g} \mathrm{mL} \mathrm{g}^{-1} \mathrm{As}(\mathrm{III})$ was prepared weekly by dilution of the respective stock solutions in u.p. water and stored at $4{ }^{\circ} \mathrm{C}$ until use. Reference solutions of As(III) were prepared daily by stepwise dilution of the respective working standard solutions in u.p. water. The $0.05 \% \mathrm{~m} / \mathrm{v}$ DDTC solution was prepared daily by dissolution of the reagent in a buffer solution (0.03 $\left.\mathrm{mol} \mathrm{L}^{-1} \mathrm{CH}_{3} \mathrm{COOH}-0.06 \mathrm{~mol} \mathrm{~L}^{-1} \mathrm{NH}_{3}, \mathrm{pH}=9.0\right)^{24}$ and was kept in dark condition with the container wrapped with tracing paper during its use.

Water samples were obtained from two ponds in Concepcion, Chile (Lo Mendez and Lo Galindo ponds) and an underground well. These samples were collected in polypropylene bottles, transported immediately to the laboratory, filtered through $0.45-\mu$ membranes and stored at $4{ }^{\circ} \mathrm{C}$ at their natural $\mathrm{pH}$ (measured between $5.0-5.9$ ) until analysis. Arsenic determinations were performed within $48 \mathrm{~h}$ after sample collection.

Glass and plastic materials were cleaned as described elsewhere ${ }^{8}$.

\section{Procedure for the on-line pre-concentration - elution}

The flow system manifold used for on-line pre-concentration and elution is shown in Figure 1 (elution step) and was operated in a timebased mode. The steps of the complete sequence, the optimized operating parameters (flow and time), the active peristaltic pumps, the flow-rates and media, the valves actions, the autosampler arm position, and the description of each function are given in Table 1, and the thermal program conditions of the TCA are shown in Table 2.

Two rinse steps and a water removal step by air preceded the preconcentration with the IV in the injection position and the autosampler arm in the waste position. First, a rinse step with ethanol (13 s) was used to eliminate from the $\mathbf{M C}$ and tubing connectors any residues of arsenic(III) or other metal DDTC chelates; second, a rinse step with water (11 s) was applied to eliminate ethanol residues from the MC and tubing lines; and third, an air flow (12 s) was employed to remove any water residue before the start of the pre-concentration step. In parallel with these 3 steps, the sample, $\mathrm{HCl}$ and DDTC solutions are purged through the tubing lines and IV to waste. In the preconcentration step, the IV changed to the load position and $1.7 \mathrm{~mL}$ of the sample or reference solutions containing between $0.25-6.0 \mu \mathrm{g} \mathrm{L}^{-1}$ As(III) on-line adjusted to $\mathrm{pH} 1.5$ (with $0.6 \mathrm{~mL}$ of $0.6 \% \mathrm{~m} / \mathrm{v} \mathrm{HCl}$ solution) and mixed with $0.05 \% \mathrm{~m} / \mathrm{v}$ DDTC solution $(0.95 \mathrm{~mL})$ were pumped through the MC during $30 \mathrm{~s}$ and the effluent was directed towards waste. Arsenic(III) was extracted by chelation with DDTC and by sorption on the $\mathrm{C} 18$ reverse phase MC. After the preconcentration step, a wash step was performed with u.p. water for $10 \mathrm{~s}$ $(0.6 \mathrm{~mL})$ in the same direction of the sample load in the MC to eliminate interfering matrix residues and excess reagents, with the IV in the load position. Then, the IV changed from load to injection position, a water removal step by an air flow ( $23 \mathrm{~s}$ ) was used to eliminate water residue from the $\mathbf{M C}$ and tubing connections, and at this stage the autosampler arm was automatically moved to the tungsten coil for eluate injection. The two water flows were conducted in opposite directions regarding the micro-column to better rinsing of the column and to reduce column compactness, and for this task they were commuted independently (V6 and V7). The elution step was performed in two 2-s elution periods and ethanol was the eluent at a flow-rate of $1.1 \mathrm{~mL} \mathrm{~min}^{-1}$. The first elution period was followed by three intervals of eluate delivery into the tungsten coil pushed by an air flow, alternated with one air flow stop and two drying and cooling intervals of the tungsten coil respectively (see Table 1 ). The air flow stop was necessary first, to avoid delivery in one air pulse of the full eluate fraction into the coil, which could saturate its sample capacity causing physical sample loss, and second, to enable accurate eluate volume injection. The drying and cooling intervals were needed to eliminate the solvent and prepare the coil for receiving the next eluate fraction respectively. The second elution period was followed analogously by two intervals of eluate delivery into the tungsten coil, the first one was followed by drying and cooling times, and the second one was followed by a drying time with the autosampler arm moving automatically to the waste position at the end of this period. The total eluate volume injected into the coil was $71 \pm 2 \mu \mathrm{L}$ and was determined by repetitive weight measurements made in a polypropylene microtube. The thermal program of the TCA (Table 2) includes fourteen steps and runs in parallel with the pre-concentration in the flow system. It is synchronized to start with two drying steps ( 1 and 2 ) followed by two cooling steps (3 and 4), the atomization (5) and the cleaning step (6), enabling a cleanout of the tungsten coil before the first eluate fraction is injected onto the coil at step 7. Five eluate fractions are injected onto the coil divided into two fractions at step 7 and one fraction at steps 9, 11 and 13 respectively, followed by drying at steps 8, 10, 12, 14, 1 and 2 respectively. Cooling at step 3 enables the attainment of a higher temperature gradient during atomization ${ }^{9}$, and a short cooling at step 4 triggers the spectrometer read out, few milliseconds before the start of the atomization step.

The use of one injection valve and two peristaltic pumps is not strictly necessary in this pre-concentration scheme; however, the injection valve was already available in our laboratory and was used previously in the pre-concentration of $\mathrm{Cd}$ and $\mathrm{Pb}$ in which a micro- 
Table 1. Steps and actions in the flow system for As(III) determination by TCA-AAS with on-line preconcentration / separation ${ }^{\mathrm{a}}$

\begin{tabular}{|c|c|c|c|c|c|c|c|c|}
\hline \multirow[b]{2}{*}{ Step } & \multirow[b]{2}{*}{$\begin{array}{c}\text { Time } \\
\text { (s) }\end{array}$} & \multicolumn{2}{|r|}{ P1 } & \multicolumn{2}{|r|}{$\mathrm{P} 2$} & \multirow[b]{2}{*}{$\begin{array}{c}\text { S.V. } \\
\text { actives }\end{array}$} & \multirow[b]{2}{*}{$\begin{array}{c}\text { IV } \\
\text { position }\end{array}$} & \multirow[b]{2}{*}{ Action } \\
\hline & & $\begin{array}{c}\text { Flow } \\
\left(\mathrm{mLmin}^{-1}\right)\end{array}$ & Medium & $\begin{array}{c}\text { Flow } \\
\left(\mathrm{mLmin}^{-1}\right)\end{array}$ & Medium & & & \\
\hline \multirow[t]{5}{*}{1} & 3 & - & - & - & - & - & - & START. Autosampler arm moves to waste position. \\
\hline & 13 & - & - & 1.1 & Ethanol & V3 & Injection $^{\mathrm{b}}$ & Rinse with ethanol (MC and tubing). \\
\hline & & 3.4 & Sample & - & - & V1 & $"$ & Purge with sample solutions (and tubing, IV) \\
\hline & & 1.2 & $\mathrm{HCl}$ & - & - & $\mathrm{V} 1^{\prime}$ & ” & Purge with $\mathrm{HCl}$ solutions (and tubing, IV) \\
\hline & & 1.9 & DDTC & - & - & V5 & ” & Purge with DDTC solutions (and tubing, IV) \\
\hline 2 & 11 & - & - & 3.4 & Water & V6 & Injection & Rinse with water (MC and tubing) \\
\hline 3 & 12 & 3.5 & Air & - & - & V4 & Injection & Water removal with air (MC and tubing) \\
\hline \multirow[t]{4}{*}{4} & 4 & - & - & - & - & - & Load $^{\mathrm{c}}$ & IV change from Injection to Load for pre-concentration \\
\hline & 30 & 3.4 & Sample & - & - & V1 & ” & Sample introduction into the flow system \\
\hline & & 1.2 & $\mathrm{HCl}$ & - & - & V1' & ” & Sample acidification with $\mathrm{HCl}$ solution \\
\hline & & 1.9 & DDTC & - & - & V5 & & $\begin{array}{l}\text { As(III) chelation with DDTC and sorption of the } \\
\text { complex in MC }\end{array}$ \\
\hline \multirow[t]{2}{*}{5} & 10 & - & - & 3.7 & Water & V7 & Load & Rinse of MC and tubing with water \\
\hline & 5 & - & - & - & - & - & Injection & Change of IV from Load to Injection for elution \\
\hline \multirow[t]{2}{*}{6} & 23 & 3.5 & Air & - & - & V4 & Injection & Water removal with air (MC and tubing) \\
\hline & 5 & - & - & - & - & - & $"$ & Autosampler arm moves to on top of tungsten coil \\
\hline \multirow[t]{15}{*}{7} & 2 & - & - & 1.1 & Ethanol & V3 & Injection & First elution fraction with ethanol \\
\hline & 2 & 3.5 & Air & - & - & V4 & " & Eluate delivery into the tungsten coil with air flow \\
\hline & 2 & - & - & - & - & - & ” & $\begin{array}{l}\text { Stop of air flow to avoid delivery in one air pulse of the } \\
\text { full eluate fraction into the tungsten coil }\end{array}$ \\
\hline & 4 & 3.5 & Air & - & - & V4 & $"$ & Eluate delivery into the tungsten coil with air flow \\
\hline & 15 & - & - & - & - & - & ” & Drying of eluate in the tungsten coil $(0.60 \mathrm{~V})$ \\
\hline & 4 & - & - & - & - & - & ” & Cooling of the coil \\
\hline & 5 & 3.5 & Air & - & - & V4 & ” & Eluate delivery into the tungsten coil with air flow \\
\hline & 15 & - & - & - & - & - & ” & Drying of eluate in the tungsten coil $(0.70 \mathrm{~V})$ \\
\hline & 4 & - & - & - & - & - & ” & Cooling of the coil \\
\hline & 2 & - & - & 1.1 & Ethanol & V3 & $"$ & Second elution fraction with ethanol \\
\hline & 6 & 3.5 & Air & - & - & V4 & " & Eluate delivery into the tungsten coil with air flow \\
\hline & 8 & - & - & - & - & - & " & Drying of eluate in the tungsten coil $(0.70 \mathrm{~V})$ \\
\hline & 5 & - & - & - & - & - & ” & Cooling of the coil \\
\hline & 6 & 3.5 & Air & - & - & V4 & ” & Eluate delivery into the tungsten coil with air flow \\
\hline & 12 & - & - & - & - & - & ” & Drying of eluate in the tungsten coil $(0.85 \mathrm{~V})$. END \\
\hline
\end{tabular}

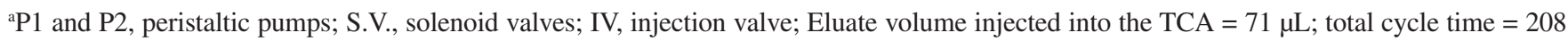
s. ${ }^{b}$ Elution position. ${ }^{\mathrm{c}}$ Loading of the MC with sample.

Table 2. Thermal heating program of the TCA for As(III) determination by TCA-AAS with on-line pre-concentration/separation ${ }^{a}$

\begin{tabular}{lcccc}
\hline Step & Time $(\mathrm{s})$ & Voltage $(\mathrm{V})$ & Temperature $\left({ }^{\circ} \mathrm{C}\right)$ & Read $^{\mathrm{b}}$ \\
\hline 1 & 75 & 0.80 & 380 & \\
2 & 20 & 0.75 & 350 & \\
3 & 10 & 0.0 & 20 & \\
4 & 0.2 & 0.0 & 20 & Yes \\
5 & 2.5 & 14.0 & 1920 & \\
6 & 3.0 & 14.0 & 1920 & \\
7 & 15.3 & 0.0 & 20 & \\
8 & 15 & 0.60 & 300 & \\
9 & 9 & 0.0 & 20 & \\
10 & 15 & 0.70 & 325 & \\
11 & 12 & 0.0 & 20 & \\
12 & 8 & 0.70 & 325 & \\
13 & 11 & 0.0 & 20 & \\
14 & 12 & 0.85 & 405 & \\
\hline
\end{tabular}

aluate volume injected into the TCA $=71 \mu \mathrm{L}$; total time $=208 \mathrm{~s}$; ${ }^{\mathrm{b}}$ Spectrophotometer read out. column was connected to the injector rotor according to Fang et al. ${ }^{28}$. The injection valve can be replaced by using a similar configuration as the approach used by Silva et al. ${ }^{14}$. The use of two peristaltic pumps was found more convenient to have independent control of the flow of ethanol and the two water flows according to our stock of tubing with appropriate inner diameters, and this was done by Pump 2. However, these flows can be controlled too by a unique pump.

\section{RESULTS AND DISCUSSION}

According to previous work done in this laboratory, As was determined directly by TCA-AAS using Rh $(2.0 \mu \mathrm{g})$ as chemical modifier $^{12}$ and the detection limit was $2.9 \mu \mathrm{g} \mathrm{\textrm {L } ^ { - 1 }}(10 \mu \mathrm{L}$ injection volume), which is insufficient for its determination in natural waters in which As may be present at sub-ppb levels. The need for preconcentration of As(III) in water samples is because most of the inorganic As content in natural waters, except for the existence of a reductive medium, is at the $\mathrm{As}(\mathrm{V})$ oxidation $\mathrm{stat}^{24}$. Hence, there is a strong need to concentrate the trace levels of As(III) before its determination in water samples. Moreover, the direct determination of As by TCA-AAS using Rh $(2.0 \mu \mathrm{g})$ modifier is affected mainly by the presence of $\mathrm{P}_{\text {as }} \mathrm{PO}_{4}^{3-}$, and to lesser extent by $\mathrm{Fe}^{3+}$ and $\mathrm{Ca}^{2+}$; the 
largest effect is an absorbance signal depression by $\mathrm{PO}_{4}^{3-29}$. On the contrary, $\mathrm{Mg}^{2+}$ compensates the depression produced by $\mathrm{Fe}^{3+}$ and $\mathrm{Ca}^{2+}$, however, it does not counteract the $\mathrm{PO}_{4}^{3-}$ interference effect ${ }^{29}$. The use of a flow system with a pre-concentration and matrix separation approach in synchronism with parallel heating of a TCA eliminates matrix interference effects and makes possible to lower the detection limit, enabling the determination of As(III) at sub-ppb levels in waters as is described ahead.

\section{Optimization of the flow system}

Initially a flow system with pre-concentration/separation using a $60 \mathrm{mg}$ micro-column and manual injection into the TCA was built in order to find out preliminary conditions for the pre-concentration of As(III), based on a previously described flow injection system applied in ET-AAS with graphite furnace ${ }^{24}$. Thereafter, the flow system was configured with a $5 \mathrm{mg}$ micro-column, and it was necessary to elaborate software ad hoc to enable a complete examination of the different actions to trigger and to block each device utilized in the flow system already described. The sequence is indicated in Table 1. The software itself is open and was designed with flexibility to enable changes in programming and in the conditions of all valves set up, autosampler arm position and tungsten coil heating. It controls twenty five different actions and it was necessary to begin with three purge steps (ethanol, water and air), followed by the pre-concentration step, the washing step and the elution step with the eluate delivery by an air flow into the tungsten coil, alternated with drying and cooling periods. The thermal program of the TCA (Table 2) was started synchronously with the flow system sequence and both run in parallel. Due to the difference in response time between the solenoid valves $(20-30 \mathrm{~ms})$, the injection valve (ca. $1 \mathrm{~s}$ ), and the autosampler arm (movement from the waste to the tungsten coil position, $c a .3 \mathrm{~s}$ ) it was essential to find exact synchronization between these items using a digital multimeter and a chronometer for voltage ( 0 or $12 \mathrm{~V} \mathrm{DC}$ ) and time measurements, respectively. The minimum response time was determined by the solenoid valves and a Pentium $100 \mathrm{PC}$ was sufficient to handle this software. The system was tested with As(III) reference solutions (2.0 and $6.0 \mu \mathrm{g} \mathrm{L}^{-1}$ ) using a $10-\mu \mathrm{L}$ filled MC obtaining satisfactory analytical absorption signals without background (Figure 2), and also the blank absorption with u.p. water was consistently low. As is shown in Figure 2 the absorption signal obtained for As(III) is of short duration $(300 \mathrm{~ms})$ and background absorption is not significant.

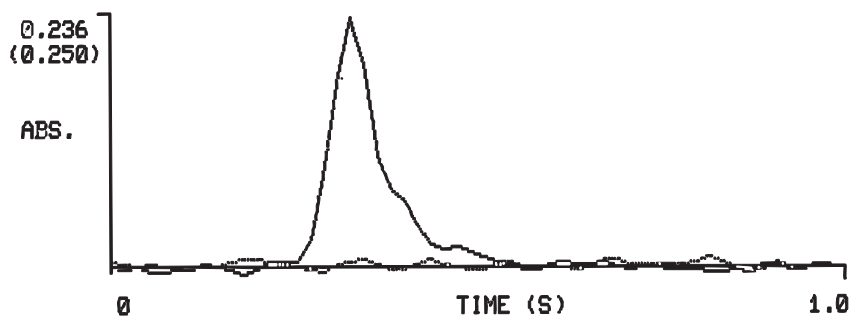

Figure 2. Specific absorption signal of $6.0 \mu \mathrm{g} \mathrm{L}^{-1} \mathrm{As}(\mathrm{III})$ and background absorption signal obtained after $30 \mathrm{~s}$ pre-concentration using the flow system with on-line separation and pre-concentration coupled to TCA-AAS

In the approach used in this work, the short reaction tubing (Fig. 1) is possible because of the fast As(III)-DDTC complex formation ${ }^{24}$ which occurs before the decomposition of the DDTC, being this complex more stable than the DDTC itself in acid solution. Thus, extraction of this complex by sorption in the MC precludes possible equilibria changes between $\mathrm{As}(\mathrm{III})$ and $\mathrm{As}(\mathrm{V})$ which still could alter

the original sample composition with respect to the individual species during analysis by other analytical methods ${ }^{24}$.

\section{Analytical figures of merit}

A comparison was made of calibration curves obtained for different pre-concentration times as is shown in Figure 3. As expected the slope of the curve increased with pre-concentration time between 15 and $60 \mathrm{~s}$. Though, a $30 \mathrm{~s}$ pre-concentration was selected because the slope was higher by $36 \%$ with respect to that obtained for $15 \mathrm{~s}$ pre-concentration, and further increase with pre-concentration time was only by $18 \%$ for $60 \mathrm{~s}$ respect to the slope obtained for $30 \mathrm{~s}$. The pre-concentration coefficient achieved with $30 \mathrm{~s}$ pre-concentration was 28.9 and was satisfactory for the determination of As(III) at sub-ppb levels found in unpolluted waters, whereas the concentration efficiency ${ }^{30}$ was $8.3 \mathrm{~min}^{-1}$.

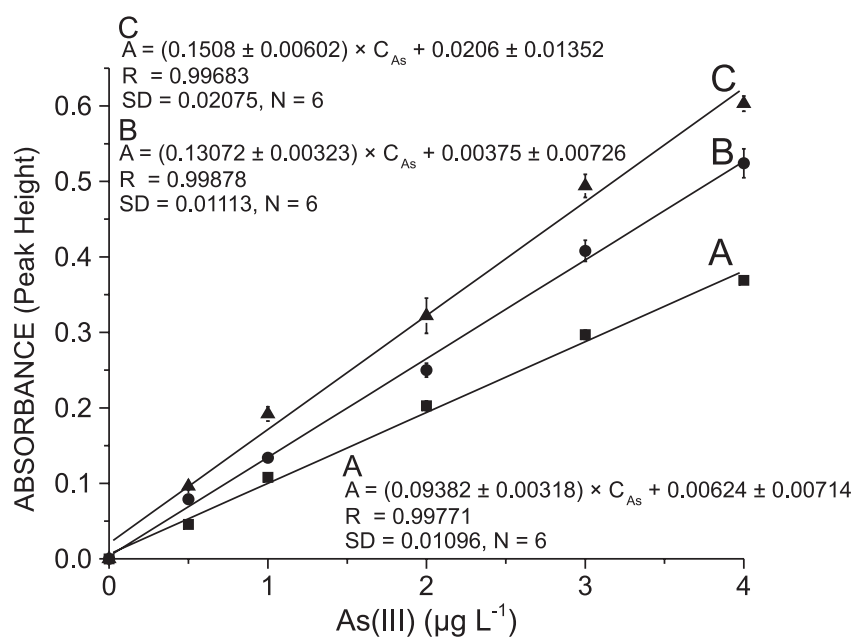

Figure 3. Calibration curves obtained for As(III) with three pre-concentration periods $(\boldsymbol{A}=15 \mathrm{~s} ; \boldsymbol{B}=30 \mathrm{~s} ; \boldsymbol{C}=60 \mathrm{~s})$ using the flow system with on-line separation and pre-concentration coupled to TCA-AAS

In Table 3 are shown the analytical figures of merit obtained for As(III) determination with this system using a 30 s pre-concentration time. The calibration curve was linear for more than one order of magnitude with satisfactory correlation and fair standard error of the estimate $\left(S_{y x}=0.01113\right)$; it was obtained with 9 experimental points, each one corresponding to the mean of at least five measurements. The sensitivity and the detection limit were comparably better by a factor of 2 respectively, than those obtained with the same preconcentration system using graphite furnace atomization and $60 \mathrm{~s}$ pre-concentration time ${ }^{24}$. The better detection limit obtained in the present work (4.1 pg) is related with the injection of the full eluate volume $(71 \mu \mathrm{L})$ whereas in previous approach ${ }^{24}$ the eluate injection

Table 3. Analytical figures of merit for As(III) determination by TCAAAS with on-line pre-concentration/separation.

Characteristic mass (pg)

Linear working range $\left(\mu \mathrm{g} \mathrm{L}^{-1}\right)$

Correlation coefficient

Reciprocal sensitivity $\left(\mu \mathrm{g} \mathrm{L}^{-1}\right)$

Repeatability (\% C.V.)

Detection limit ${ }^{\mathrm{a}}\left(\mu \mathrm{g} \mathrm{L}^{-1}\right)$

Quantification limit ${ }^{\mathrm{b}}\left(\mu \mathrm{g} \mathrm{L}^{-1}\right)$

Mean recovery (\%)

a $3 \sigma_{\mathrm{BL}} /$ slope; ${ }^{\mathrm{b}} 10 \mathrm{x} \sigma_{\mathrm{BL}} /$ slope.

\section{8}

$0.25-6.0$

0.9976

0.034

3.4

0.058

0.19

107 
was limited to a fraction of $40 \mu \mathrm{L}$ which is the capacity limit of the graphite tube. Also, good repeatability was achieved and was attributed to the accurate timing and synchronization of the solenoid valves, injection valve and heating program of the TCA via software. Previously, Silva et al. ${ }^{14}$ coupled a flow injection system to a tungsten coil atomizer for on-line separation and pre-concentration using a micro-column packed with $5 \mathrm{mg}$ Chelex-100 in the tip of the autosampler arm and lead as model element, and elution was performed automatically by sampling $20 \mu \mathrm{L}$ of the eluent, attaining a detection limit of $75 \mathrm{ng} \mathrm{L}^{-1}$ and a sample frequency of $30 \mathrm{~h}^{-1}$. This interesting alternative which was applied previously in graphite furnace AAS as indicated in the references therein ${ }^{14}$, was experienced by Silva et al. for the first time coupled with TCA-AAS. Compared with their achievements, in the present work using a micro-column packed with $5 \mathrm{mg} \mathrm{C} 18$ reverse phase connected as a loop in the injector rotor of the injection valve, it was possible to elute and inject into the coil a total volume 3.5 times higher $(71 \mu \mathrm{L})$, enabling a comparative detection limit and repeatability, despite the use of fractionate elution and injection into the coil alternated with drying and cooling periods of the TCA. However, the larger injection volume is obviously at the expense of a reduced sample throughput (17 $\mathrm{h}^{-1}$ ). The low detection limit obtained for As(III) was possible due to the low background absorption obtained despite the relatively large injection volume. The pre-concentration coefficient informed by Silva et al. for $\mathrm{Pb}$ was 64 using $60 \mathrm{~s}$ pre-concentration time $(3 \mathrm{~mL})$, whereas in the present work this figure for As was 28.9 using $30 \mathrm{~s}$ preconcentration time $(1.7 \mathrm{~mL})$. Besides the difference in analytes and pre-concentration approaches, this difference might be attributed in part to the different pre-concentration times.

An analytical recovery study performed in triplicate with reference solutions containing $0.25 \mu \mathrm{g} \mathrm{L}^{-1}$ of As(III) provided a mean \pm standard deviation of $0.267 \pm 0.004$, with a recovery between $105-$ $108 \%$, which is quite satisfactory considering the relatively low As(III) concentration used in this study. The same study was performed for $0.50 \mu \mathrm{g} \mathrm{L}^{-1}$ of As(III) in the presence of $0.50 \mu \mathrm{g} \mathrm{L}^{-1}$ of $\mathrm{As}(\mathrm{V})$ and the recovery was $104 \%$. Thus, the recovery of As(III) in the presence of $\mathrm{As}(\mathrm{V})$ was satisfactory. The $\mathrm{MC}$ is simple, of low cost and its useful lifetime was 200-300 pre-concentration cycles before replacement.

\section{Applications}

In Table 4 are presented the results obtained by TCA-AAS with the pre-concentration/separation approach in the determination of As(III) in five samples of natural waters collected in the Concepcion (Chile) area (pond and underground waters), and also in a recovery study performed in these samples. Arsenic(III) was present at subppb levels in all samples and the background absorbance levels were significantly low with respect to the corresponding levels obtained in the direct sample injection into the TCA. A recovery study performed in these samples spiked with $0.50 \mu \mathrm{g} \mathrm{L} \mathrm{L}^{-1}$ of As(III) provided a mean of $89 \pm 6.5 \%(n=3)$ in underground water and $93.5 \pm 10.1 \%$ $(n=12)$ in pond waters, which can be considered satisfactory according to the low As levels used in this study. The mean analytical recovery of $\mathrm{As}(\mathrm{III})$ at a concentration of $0.5 \mu \mathrm{g} \mathrm{L}^{-1}$ in these five natural water samples was $92.6 \pm 9.5 \%(n=15)$, a quite satisfactory result considering that in previous work the recovery of As by TCA-AAS without pre-concentration in a certified reference material of "Oyster Tissue" ( $\left.\mathrm{N}^{\circ} \mathrm{CRM}-\mathrm{OT}\right)$ prepared in $5.0 \% \mathrm{HNO}_{3}$ solution from high purity standards containing $100 \pm 0.5 \mu \mathrm{g} \mathrm{L}{ }^{-1} \mathrm{As}(\mathrm{V})$, was $102 \pm 3 \%$ $(n=4)^{12}$. No further recovery studies were made by TCA-AAS for lower As concentrations without pre-concentration.

\section{CONCLUSIONS}

The flow system using a pre-concentration/separation scheme in synchronism with parallel heating of a TCA, enabled the preconcentration of As(III) by sorption of the As(III) -DDTC complex using a micro-column packed with $5 \mathrm{mg}$ C18 reverse phase, and elution with ethanol. Pre-concentration, matrix separation and heating of the TCA with full analyte injection into the tungsten coil was possible in $208 \mathrm{~s}$ per sample $\left(17 \mathrm{~h}^{-1}\right)$ which reduces significantly the analysis time for this determination compared to multi-step procedures consisting of chelation, solvent extraction, phase separation, evaporation and possibly back extraction into a suitable phase prior to quantification. Separation of the analyte from the matrix undoubtly enhances the performance of TCA-AAS and provides higher freedom from interferences than is typically achievable with hydride generation AAS. Also, the on-line procedure in a closed system reduces contact with the environment and minimizes contamination risk. The satisfactory retention efficiency of the microcolumn $(94 \pm 1 \%)$, the low detection limit $\left(0.058 \mu \mathrm{g} \mathrm{L}^{-1}\right)$, the good mean repeatability $(3.4 \%)$ and the acceptable mean analytical recovery of As(III) obtained in natural waters $(92.6 \pm 9.5 \%)$ indicate that the system can be suitable for routine analysis of As(III) at low trace levels in natural water samples. The precise timing of the flow system guarantees an accurate analysis under such conditions and precludes interferences due to kinetic effects. Additionally, this flow system may be applicable too for the on line pre-reduction of As(V) to As(III) in the determination of total inorganic As by TCA-AAS, and also for other metals forming DDTC complexes.

\section{ACKNOWLEDGMENTS}

The authors are grateful to the Fondo Nacional de Desarrollo Científico y Tecnológico (FONDECYT, Research Grant No. 1030693) and to the Dirección de Investigación of the Universidad de Concepción, Concepción, Chile (DIUC Research Grant No. 200.071.042-1.0) for financial support. Also, we are thankful to Mr. J. Vega M. of the Faculty of Chemical Sciences for his support and cooperation in the modification of the interface.

Table 4. Concentration and recovery of As(III) in natural waters by TCA-AAS with on-line pre-concentration/separation

\begin{tabular}{|c|c|c|c|c|}
\hline \multirow[t]{2}{*}{ Sample } & \multirow[t]{2}{*}{$A s^{\mathrm{a}}\left(\mu \mathrm{g} \mathrm{L}^{-1}\right)$} & \multicolumn{2}{|c|}{ As $\left(\mu \mathrm{g} \mathrm{L}^{-1}\right)$} & \multirow[t]{2}{*}{ Recovery ${ }^{\mathrm{a}} \%$} \\
\hline & & Added & Found ${ }^{a, b}$ & \\
\hline Underground water & $<0.19^{c}$ & 0.50 & $0.44 \pm 0.03$ & $88.8 \pm 6.5$ \\
\hline Laguna Lo Mendez 1 & $0.207 \pm 0.011$ & 0.50 & $0.44 \pm 0.05$ & $87.1 \pm 9.7$ \\
\hline Laguna Lo Mendez 2 & $0.225 \pm 0.002$ & 0.50 & $0.45 \pm 0.06$ & $90.2 \pm 11.4$ \\
\hline Laguna Lo Galindo 1 & $<0.19$ & 0.50 & $0.48 \pm 0.03$ & $95.5 \pm 6.0$ \\
\hline Laguna Lo Galindo 2 & $<0.19$ & 0.50 & $0.51 \pm 0.06$ & $101 \pm 11.6$ \\
\hline
\end{tabular}

${ }^{\mathrm{a}}$ Mean \pm standard deviation; $\mathrm{n}=3$; ${ }^{\mathrm{b}}$ calculated after subtraction of the intrinsic As concentration in each sample.; ${ }^{\mathrm{c}}$ quantification limit. 


\section{REFERENCES}

1. Ruzicka J.; Hansen E. H.; Flow-Injection Analysis, $2^{\text {nd }}$ ed., John Wiley \& Sons: New York, 1988.

2. Gates, S. C.; Becker, J.; Laboratory Automation using the IBM PC, Prentice Hall: Englewood Cliffs, 1989.

3. Kost, G. J.; Handbook of Clinical Automation, Robotics, and Optimization, John Wiley \& Sons, Inc.: New York, 1996.

4. http://www.vispro.de, accessed in December 2003.

5. http://www.laboratoryequipment.com, accessed in January 2004.

6. http://www.ark-plas.com, accessed in January 2004.

7. Berndt, H.; Schaldach, G.; J. Anal. At. Spectrom. 1988, 3, 709.

8. Bruhn, C. G.; Ambiado, F. E.; Cid, H. J.; Woerner, R.; Tapia, J.; Garcia, R.; Anal. Chim. Acta 1995, 306, 183.

9. Bruhn, C. G.; Neira, J. Y.; Valenzuela, G. D.; Nóbrega, J. A.; J. Anal. At Spectrom. 1998, 13, 29.

10. Bruhn, C. G.; Neira, J. Y.; Valenzuela, G. D.; Nóbrega, J. A.; Talanta 1999, 48, 537.

11. Bruhn, C. G.; Neira, J. Y.; Guzmán, M. L.; Darder, M. M.; Nóbrega, J. A.; Fresenius J. Anal. Chem. 1999, 364, 273

12. Bruhn, C. G.; Huerta, V. N.; Neira, J. Y.; Anal. Bioanal. Chem. 2004, 378, 447.

13. Rocha, F. R. P.; Reis, B. F.; Zagatto, E. A. G.; Lima, J. L. F. C.; Lapa, R A. S.; Santos, J. L. M.; Anal. Chim. Acta 2002, 468, 119.

14. Silva, M. M.; Krug, F. J.; Oliveira, P. V.; Nóbrega, J. A.; Reis, B. F.; Penteado, D. A. G.; Spectrochim. Acta, Part B 1996, 51, 1925.
15. Silva, M. M.; Arruda, M. A. Z.; Krug, F. J.; Oliveira, P. V.; Queiroz, Z. F.; Gallego, M.; Valcárcel, M.; Anal. Chim. Acta 1998, 368, 225.

16. Saha, J. C.; Dikshit, A. K.; Bandyopadhyay, M.; Saha, K. C.; Crit. Rev. Environ. Sci. Technol. 1999, 29, 281.

17. Montoro, R.; Velez, D.; Abstracts of the III Symposium of the Latinamerican and Caribean Section AOAC International, Santiago, Chile, 1999.

18. Gidhagen, L.; Kahelin, H.; Schmidt - Thomé, P.; Johansson, C.; Atmos. Environ. 2002, 36, 3803.

19. Chilean wastewater directive; D.S. N ${ }^{\circ} 90 / 00$ Ministry of the General Secretary of the Presidency, Santiago, Chile, 2000.

20. Chilean drinking water directive; NCh409/1.Of84 National Institute of Normalization, Santiago, Chile, 1984.

21. Christen, K.; Environ. Sci. Technol. 2000, 34, 291A.

22. Fang, Z.; Guo, T.; Welz, B.; Talanta 1991, 38, 613.

23. Ruzicka, J.; Arndal, A.; Anal. Chim. Acta 1989, 216, 243

24. Sperling, M.; Yin, X.; Welz, B.; Spectrochim. Acta, Part B 1991, 46, 1789.

25. Neira, J. Y.; Valenzuela, G.; Vega, J.; Moya, J.; Bruhn, C. G.; Quim. Nova 1998, 21, 490.

26. Neira, J. Y.; Reyes, N.; Nóbrega, J. A.; Lab. Rob. Autom. 2000, 12, 246.

27. Noggle, J. H.; QuickBasic Programming for Scientists and Engineers, CRC Press: Boca Raton, FL, 1993.

28. Fang, Z.; Sperling, M.; Welz, B.; J. Anal. At. Spectrom. 1990, 5, 639.

29. Bruhn, C.; unpublished results.

30. Fang, Z.; Flow Injection Separation and Preconcentration, VCH: Weinheim 1993. 